
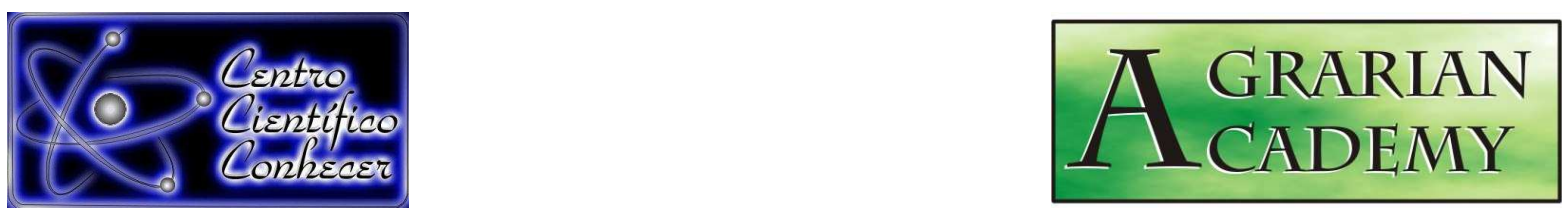

\title{
USO DO ÁCIDO SULFÚRICO E NITRATO DE POTÁSSIO NO TESTE DE GERMINAÇÃO DE Brachiaria brizantha cv. MARANDU
}

Fábio Janoni Carvalho ${ }^{1}$, Lívia Mendonça de Aguiar $^{2}$, Luciana Alves de Sousa ${ }^{3}$

${ }^{1}$ Msc. Eng. Agr., da Universidade Federal de Uberlândia (fabiojanoni@ufu.br), Uberlândia-Minas Gerais

${ }^{2}$ Bióloga, Mestranda em Qualidade Ambiental da Universidade Federal de Uberlândia

${ }^{3}$ Msc. Bióloga, da Universidade Federal de Uberlândia- Campus Monte Carmelo

Recebido em: 16/11/2015 - Aprovado em: 10/12/2015 - Publicado em: 21/12/2015 DOI: http://dx.doi.org/10.18677/Agrarian_Academy_020

\section{RESUMO}

A espécie Brachiaria brizantha é a mais cultivada no país e com maior volume de sementes destinadas a exportação. Apesar da evidente importância da dormência em sementes recém-colhidas de Brachiaria, os mecanismos que estão envolvidos na superação da dormência que ocorre durante o armazenamento ainda são pouco elucidados. O objetivo do presente trabalho foi identificar os efeitos do prétratamento com ácido sulfúrico combinado com a adição de diferentes concentrações de nitrato de potássio em sementes de B. brizantha cv. Marandu no intuito de estudar seus efeitos na dormência desta cultivar e a correlação entre ambos tratamentos. O experimento foi conduzido em Germinadores do tipo BOD, com fotoperíodo de 12 horas e alternância na temperatura de $15^{\circ} \mathrm{C}$, durante a noite, e $35^{\circ} \mathrm{C}$, durante o dia, seguindo as normas da Regra de Análise de Sementes. As sementes foram acondicionadas sobre papel do tipo germtest em caixas Gerbox. $\mathrm{O}$ experimento consistiu em um fatorial (4x2) com quatro doses de $\mathrm{KNO}_{3}$, com ou sem pré-tratamento com $\mathrm{H}_{2} \mathrm{SO}_{4}$. As variáveis analisadas foram submetidas ao teste de $\mathrm{F}$ (ANOVA) a $1 \%$ de significância, após o atendimento das pressuposições do modelo. Recomenda-se a utilização do pré-tratamento com ácido sulfúrico para a espécie por 15 minutos para quebra de dormência melhorando a germinação e reduzindo o período do teste. Entretanto este procedimento deve ser realizado por pessoal treinado, pois a utilização do ácido sulfúrico envolve riscos à saúde. Nenhuma dosagem de $\mathrm{KNO}_{3}$ auxiliou na quebra de dormência, sendo esta recomendação dispensada para a cultivar.

PALAVRAS-CHAVE: campim marandu, Dormência, $\mathrm{KNO}_{3}$, Velocidade de germinação.

\section{SULPHURIC ACID AND NITRATE POTASSIUM USE IN Brachiaria brizantha cv. MARANDU GERMINATION TEST.}

\begin{abstract}
Brachiaria brizantha is the most cultivated specie in the country and has the greater volume of seed for export. Despite the obvious importance of dormancy in freshly harvested seeds of Brachiaria, the mechanisms that are involved in breaking dormancy that occurs during storage are still poorly understood. The objective of this
\end{abstract}


study was to identify the effects of pretreatment with combined sulfuric acid with different potassium nitrate concentrations in B. brizantha cv. Marandu seeds, in order to study its effects on dormancy of this cultivar and the correlation between both treatments. The experiment was conducted in BOD germinators, with photoperiod of 12 hours and alternation in temperature of $15^{\circ} \mathrm{C}$ a t night and $35^{\circ} \mathrm{C}$ during the day, following the Regra de Análise de Sementes. The seeds were placed on germtest paper in Gerbox boxes. The experiment consisted of a factorial (4x2) with four doses of $\mathrm{KNO}_{3}$, with or without pretreatment with $\mathrm{H}_{2} \mathrm{SO}_{4}$. The variables were submitted to $\mathrm{F}$ test (ANOVA) at $1 \%$ of significance, after satisfying the assumptions of the model. It is recommended the use of pretreatment with sulfuric acid to species for 15 minutes to break dormancy enhancing germination and reducing the period of test. However this procedure should be performed by trained personnel, since the use of sulfuric acid involves health risks. No dosage $\mathrm{KNO}_{3}$ assisted in breaking dormancy, which is waived for recommendation for this cultivar.

KEYWORDS: Dormancy, $\mathrm{KNO}_{3}$, germination speed, Marandu palisadegrass

\section{INTRODUÇÃO}

O Brasil detém o segundo maior rebanho bovino do mundo, com cerca de 198 milhões de animais (USDA, 2012). Gramíneas perenes cultivadas, da família Poaceae, constituem importante fonte de proteínas para a alimentação animal, devido ao baixo custo e ao alto potencial de produção (ZUFFO et al., 2014).

A espécie Brachiaria brizantha (Hochst. ex A. Rich) Stapf é a mais cultivada no país e com maior volume de sementes destinadas a exportação e se destaca entre as diferentes espécies forrageiras cultivadas no país (SILVA et al., 2014). As sementes possuem dificuldade de germinar devido à ocorrência de dormência inata ou natural, dificultando o estabelecimento e uniformidade das populações que contribui para o aparecimento de plantas infestantes nas pastagens, principalmente no estágio inicial de formação (LAGO \& MARTINS, 1998).

A baixa taxa de germinação de sementes é comum em espécies forrageiras, e as sementes não germinam mesmo quando submetidas à condições ambientais consideradas favoráveis, sendo as mesmas classificadas como dormentes. A dormência pode interferir no uso das sementes forrageiras, por impedir a germinação e interferir diretamente no estabelecimento uniforme da pastagem (COSTA et al., 2011). A dormência da B. brizantha se associa a vários fatores, dentre eles as causas físicas, provavelmente relacionadas a restrições impostas pela cobertura da semente, glumelas (lema e pálea), pericarpo e tegumento (BINOTTI et al., 2014).

A Regra para Análise de Sementes- RAS (BRASIL, 2009) recomenda que o substrato utilizado no teste de germinação seja umedecido com solução aquosa contendo nitrato de potássio $\left(\mathrm{KNO}_{3}\right)$ na concentração de $0,2 \%$. $\mathrm{O} \mathrm{KNO}_{3}$ vem sendo utilizado em vários estudos pela sua atuação na superação de dormência pelo fato do nitrato sofrer redução e passar para a forma de nitrito, acarretando a reoxidação do $\mathrm{NAD}(\mathrm{P}) \mathrm{H}$, disponibilizando o $\mathrm{NAD}(\mathrm{P})$, que atuará estimulando a via pentose fosfato e a via do ácido chiquímico, através da Eritrose-4-fosfato. Essas duas vias são de suma importância para a biossíntese de novos compostos. A via Pentose Fosfato irá sintetizar a Ribulose-5-fosfato utilizada na síntese de nucleotídeos, constituintes dos ácidos nucléicos (RNA e DNA) e síntese de coenzimas, que poderá influenciar o processo germinativo. A via do ácido chiquímico é vital para a 
biossíntese de aminoácidos essenciais (triptofano, fenilalanina e tirosina) (CARDOSO et al., 2015).

Como o revestimento das sementes pelas glumelas é um dos fatores que levam o impedimento da germinação (CÂMARA \& STACCIARINI-SERAPHIN, 2002), a RAS recomendou escarificar as sementes com ácido sulfúrico $\left(\mathrm{H}_{2} \mathrm{SO}_{4}\right)$ concentrado por no máximo 15 minutos com o objetivo da quebra de dormência física (BRASIL, 2009). Porém o método apresenta riscos operacionais aos trabalhadores, polui o ambiente e pode promover danos qualitativos às sementes (LACERDA et al., 2010).

Apesar da evidente importância da dormência em sementes recém-colhidas de Brachiaria, os mecanismos que estão envolvidos na superação da dormência que ocorre durante o armazenamento ainda são pouco elucidados. O objetivo do presente trabalho foi identificar os efeitos do pré-tratamento com ácido sulfúrico combinado com a adição de diferentes concentrações de nitrato de potássio em sementes de $B$. brizantha cv. Marandu no intuito de estudar os efeitos na dormência desta cultivar e a correlação entre ambos tratamentos.

\section{MATERIAL E MÉTODOS}

O experimento foi realizado no laboratório de Práticas Biológicas, localizado na Universidade Federal de Uberlândia Campus Monte Carmelo (1842'43,19"S e 47-29'55,8"O). Foram utilizadas sementes de $B$. brizantha cv. Marandu armazenadas por seis meses, e com germinação de $60 \%$.

O experimento foi conduzido em Germinadores do tipo BOD, com fotoperíodo de 12 horas e alternância na temperatura de $15^{\circ} \mathrm{C}$, durante a noite, e $35^{\circ} \mathrm{C}$, durante o dia, seguindo as normas da Regra de Análise de Sementes (BRASIL, 2009). As sementes foram acondicionadas sobre papel do tipo germtest em caixas Gerbox. $O$ experimento consistiu em um fatorial (4x2) com quatro doses de $\mathrm{KNO}_{3}$, com ou sem pré-tratamento com $\mathrm{H}_{2} \mathrm{SO}_{4}$ em delineamento inteiramente casualizado, com três repetições. Para as parcelas com pré-tratamento com $\mathrm{H}_{2} \mathrm{SO}_{4}$, o ácido foi aplicado por 15 minutos antes da semeadura no papel, e as sementes tratadas foram então lavadas.

As doses de $\mathrm{KNO}_{3}$ aplicadas foram $0 \% ; 0,2 \% ; 0,4 \%$ e $0,8 \%$ diluídas na água que foi aplicada no papel germitest. As quantidades de $\mathrm{KNO}_{3}$ foram pesadas em balança com variação de 4 casas decimais e então adicionadas em $1000 \mathrm{~mL}$ de água destilada. Cada caixa gerbox do tratamento correspondente foi umedecido então com a solução preparada. As parcelas consistiram de 30 sementes por caixa gerbox. A germinação foi contabilizada do dia 10 de setembro até 10 de outubro de 2014 para a quantificação das seguintes características: tempo final (tf) e médio de germinação $(\bar{t})$ (LABOURIAU, 1983); germinação $(\mathrm{G})$; velocidade média $(\bar{v})$ (LABOURIAU, 1976); índice da velocidade de germinação (IVE) (MAGUIRE, 1962); e coeficiente de variação do tempo $\left(\mathrm{CV}_{\mathrm{t}}\right)$ (RANAL \& SANTANA, 2006). Caso ocorresse diminuição da umidade do papel o mesmo era reumedecido com a referente dose de $\mathrm{KNO}_{3}$.

As variáveis analisadas foram submetidas ao teste de $\mathrm{F}$ (ANOVA) a $1 \%$ de significância, após o atendimento das pressuposições do modelo pelos testes de Shapiro-Wilk, para normalidade dos resíduos, Levene, para homogeneidade das variâncias, todos a $1 \%$ de significância. Verificado diferença entre os tratamentos o teste de Tukey foi realizado, com $5 \%$ de significância, utilizando-se o programa computacional SISVAR (FERREIRA, 2011). 


\section{RESULTADOS E DISCUSSÃO}

A partir do Quadro de análise da variância (Tabela 1), foi observado que as diferentes doses de $\mathrm{KNO}_{3}$ não afetaram em nenhum caractere germinativo da cultivar. Os resultados contrastam com aqueles encontrados por BINOTTI et al., (2014), para a B. brizantha cv. MG-5, em que a embebição das sementes com solução de $\mathrm{KNO}_{3}$ a $0,2 \%$ proporcionou diferença na germinação. Tal diferença pode ser justificada pela cultivar utilizada ser diferente, mostrando que os tratamentos para quebra de dormência podem ter efeito diferenciado até para cultivares da mesma espécie.

A interação entre os dois tratamentos utilizados também não foi observada, sugerindo que os tratamentos não trabalham de forma sinérgica nem antagônica para quebra da dormência e melhoria da germinação. Para $B$. decumbens, ambas as metodologias para quebra de dormência funcionaram de forma sinérgica para a dose de $0,2 \%$ de $\mathrm{KNO}_{3}$ (TOMAZ et al., 2015).

A utilização do pré-tratamento com $\mathrm{H}_{2} \mathrm{SO}_{4}$ afetou todas as características analisadas por exceção do índice de velocidade de emergência, que obteve média de 3,65 sementes emergidas por dia. $O$ tratamento com ácido também reduziu o número de sementes dormentes em experimento com $B$. humidicola, após períodos de armazenamento (COSTA et al., 2011).

TABELA 1. Quadro análise de variância para os caracteres germinativos de $B$. brizantha cv. Marandu submetida a diferentes doses de $\mathrm{KNO}_{3}$ e prétratamento com $\mathrm{H}_{2} \mathrm{SO}_{4}$.

\begin{tabular}{|c|c|c|c|c|c|c|}
\hline \multirow{2}{*}{ Causa da variação } & \multicolumn{3}{|c|}{ Tf } & \multicolumn{3}{|c|}{$\overline{\bar{t}}$} \\
\hline & QM & $\mathrm{F}$ & $p$-valor & QM & $\mathrm{F}$ & $p$-valor \\
\hline Dose $\mathrm{KNO}_{3}$ & 18,153 & 1,954 & 0,16 & 1,186 & 1,235 & 0,33 \\
\hline Pré-trat. $\mathrm{H}_{2} \mathrm{SO}_{4}$ & 210,042 & 22,605 & $0,00^{*}$ & 15,338 & 15,966 & $0,00^{*}$ \\
\hline Interação & 22,486 & 2,420 & 0,11 & 1,226 & 1,277 & 0,32 \\
\hline Erro & 9,292 & & & 0,961 & & \\
\hline \multirow[b]{2}{*}{ Causa da variação } & \multicolumn{3}{|c|}{$\mathrm{G}$} & \multicolumn{3}{|c|}{$\bar{v}$} \\
\hline & QM & $\mathrm{F}$ & $\begin{array}{c}p- \\
\text { valor }\end{array}$ & QM & $\mathrm{F}$ & $p$-valor \\
\hline Dose $\mathrm{KNO}_{3}$ & 100,000 & 1,701 & 0,21 & 0,001 & 0,952 & 0,44 \\
\hline Pré-trat. $\mathrm{H}_{2} \mathrm{SO}_{4}$ & 816,667 & 13,89 & $0,00^{*}$ & 0,033 & 22,685 & $0,00^{*}$ \\
\hline Interação & 203,086 & 3,454 & 0,05 & 0,002 & 1,077 & 0,39 \\
\hline Erro & 58,796 & & & 0,001 & & \\
\hline \multirow[b]{2}{*}{ Causa da variação } & \multicolumn{3}{|c|}{$\mathrm{CVt}$} & \multicolumn{3}{|c|}{$I V E$} \\
\hline & QM & $\mathrm{F}$ & $\begin{array}{c}p- \\
\text { valor }\end{array}$ & QM & $\mathrm{F}$ & $p$-valor \\
\hline Dose $\mathrm{KNO}_{3}$ & 164,007 & 0,933 & 0,45 & 0,418 & 0,887 & 0,469 \\
\hline Pré-trat. $\mathrm{H}_{2} \mathrm{SO}_{4}$ & 1527,72 & 8,690 & $0,00^{*}$ & 0,044 & 0,094 & 0,763 \\
\hline Interação & 179,792 & 1,023 & 0,41 & 1,639 & 3,473 & 0,05 \\
\hline Erro & 175,811 & & & 0,472 & & \\
\hline
\end{tabular}

* Significativo a 1\% pelo teste de F. QM: Quadrado Médio; ti: tempo da primeira germinação, tf: Tempo da última Germinação,î:Tempo Médio para a Germinação, G: Germinação, $\bar{v}$ : Velocidade Média; $\mathrm{CV}_{\mathrm{t}}$ : Coeficiente de Variação do Tempo, IVE: Velocidade de Emergência.

$\mathrm{O}$ pré-tratamento com $\mathrm{H}_{2} \mathrm{SO}_{4}$ permitiu melhoria nos caracteres germinativos (Tabela 2), com aumento em 12\% na germinação e tempo final de 6 dias, a metade comparada ao tratamento sem ácido, mostrando que além de aumentar a 
germinação, também ocorre de forma acelerada. As sementes germinaram de forma mais concentrada, como relatado pelos valores do coeficiente de variação no tempo de 27,56\%. MACEDO et al., (1994) também observaram que a aplicação de ácido sulfúrico possibilitou um aumento significativo na germinação das sementes e na uniformidade desse processo.

Para as sementes da gramínea Spermacoce latifolia, o ácido sulfúrico foi eficiente para tornar o endocarpo menos resistente, devido ao desgaste da parede, tornando-o mais permeável à entrada de água e protusão da radícula, porém a maior concentração deste ácido comprometeu as estruturas internas da semente (PARREIRA et al., 2011). A escarificação química com ácido sulfúrico é um método eficaz para superação de dormência de sementes de $B$. brizantha, porém, as mesmas ficam mais suscetíveis aos processos que levam a deterioração (CARDOSO et al., 2014).

TABELA 2. Médias para o tempo médio, germinação, velocidade média e coeficiente de variação no tempo para sementes de $B$. brizantha cv. Marandu com e sem pré-tratamento $\mathrm{com} \mathrm{H}_{2} \mathrm{SO}_{4}$ por 15 minutos.

\begin{tabular}{ccccccc}
\hline & $\mathrm{Tf}(\mathrm{dia})$ & $\overline{\bar{E}}$ (dia) & $\mathrm{G}(\%)$ & $\bar{v}\left(\mathrm{dia}^{-1}\right)$ & $C V t(\%)$ & IVE $\left({\left.\mathrm{s} . \mathrm{dia}^{1}\right)}^{\mathrm{a}}\right)$ \\
\hline $\mathrm{Com} \mathrm{H}_{2} \mathrm{SO}_{4}$ & $5,9 \mathrm{a}$ & $3,73^{\mathrm{a}}$ & $54,17 \mathrm{a}$ & $0,27^{\mathrm{a}}$ & $27,56 \mathrm{a}$ & \multirow{2}{*}{3,65} \\
$\mathrm{Sem} \mathrm{H}_{2} \mathrm{SO}_{4}$ & $11,8 \mathrm{~b}$ & $5,33 \mathrm{~b}$ & $42,50 \mathrm{~b}$ & $0,20 \mathrm{~b}$ & $43,51 \mathrm{~b}$ & \\
\hline
\end{tabular}

Médias seguidas de letras iguais, na coluna, não diferem significamente a $5 \%$ de probabilidade pelo teste de Tukey. ti: tempo da primeira germinação, tf: Tempo da última Germinação, $\bar{t}$ :Tempo Médio para a Germinação, G: Germinação, $\bar{v}$ : Velocidade Média; CV $_{\mathrm{t}}$ : Coeficiente de Variação do Tempo, IVE: Velocidade de Emergência.

A frequência de germinação permite comparar índice de sincronização da germinação na forma gráfica (BUFALO et al., 2012). Além de um pico maior, a germinação ocorreu de forma mais concentrada para as sementes que foram submetidas ao tratamento com ácido sulfúrico (Figura 1). Aliado à melhoria nos demais caracteres germinativos, o gráfico da frequência relativa corrobora a identificar o impacto positivo do tratamento com ácido sulfúrico na quebra de dormência.
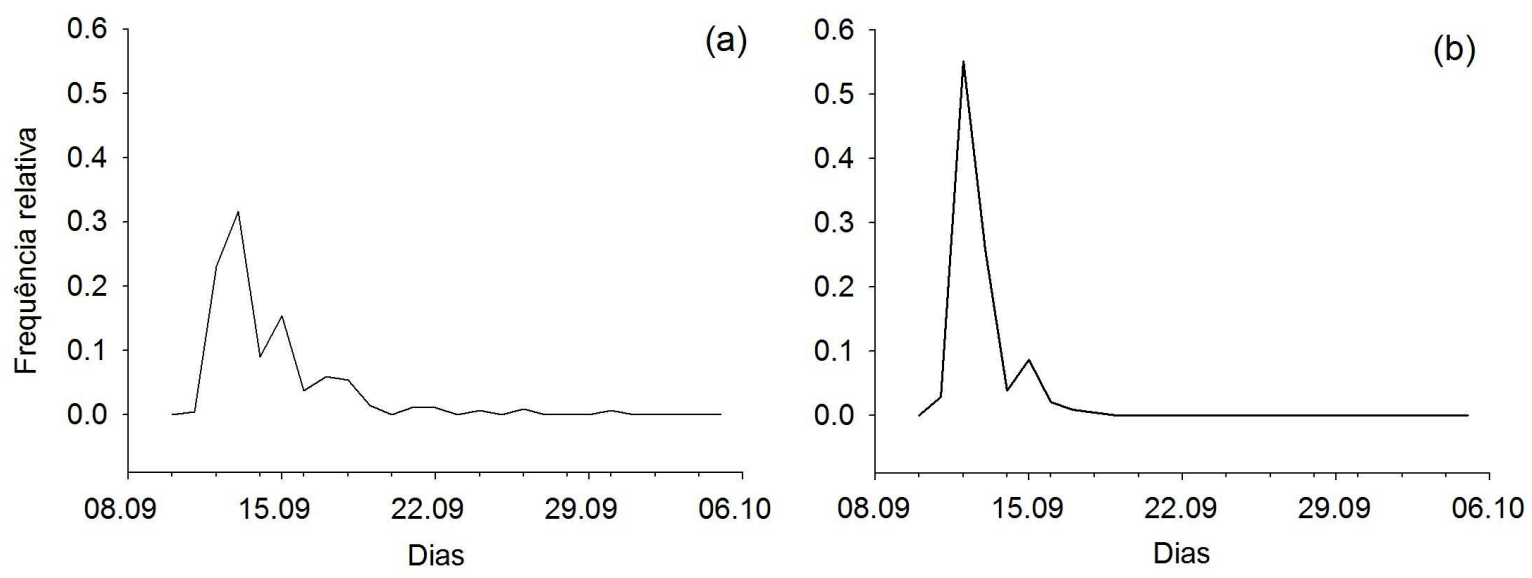

FIGURA 1. Frequência relativa da germinação de $B$. brizantha cv. Marandu submetida sem pré-tratamento com $\mathrm{H}_{2} \mathrm{SO}_{4}$ (a) e com pré-tratamento com $\mathrm{H}_{2} \mathrm{SO}_{4}$. 


\section{CONCLUSÃO}

Recomenda-se a utilização do pré-tratamento com ácido sulfúrico para a $B$. brizantha $\mathrm{cv}$. Marandu por 15 minutos para quebra de dormência melhorando a germinação e reduzindo o período do teste. Entretanto este procedimento deve ser realizado por pessoal treinado, pois a utilização do ácido sulfúrico envolve riscos à saúde. Nenhuma dosagem de $\mathrm{KNO}_{3}$ auxiliou na quebra de dormência, sendo esta recomendação dispensada para a cultivar.

\section{REFERÊNCIAS}

BINOTTI, F.F.S.; JUNIOR, C.I.S ; CARDOSO, E.D. ; HAGA, K.I.; NOGUEIRA, D.C. Tratamentos pré-germinativos em sementes de Brachiaria. Revista Brasileira de Ciências Agrárias, v.9, n.4, p.614-618, 2014. Disponível em: <http://www.redalyc.org/articulo.oa?id=119032902022>

BRASIL, Ministério da Agricultura e Reforma Agrária. Regras para análise de sementes. Brasília, Secretaria Nacional de Defesa Agropecuária, 2009. 398p.

BUfALO J.; AMARO, A.C.E.; ARAÚJO, H. S. ;CORSATO, J. M.; ONO, E. O.; FERREIRA, G.; RODRIGUES, J. D. Períodos de estratificação na germinação de sementes de alface (Lactuca sativa L.) sob diferentes condições de luz e temperatura. Semina: Ciências Agrárias, v.33, n.3, p. 931-940, 2012. Disponível em: <http://dx.doi.org/10.5433/1679-0359.2012v33n3p931> doi: 10.5433/16790359.2012v33n3p931

CÂMARA, H.H; STACCIARINI-SERAPHIN, E.S. Germinação de sementes de Brachiaria brizantha cv. Marandu sob diferentes períodos de armazenamento e tratamento hormonal. Pesquisa Agropecuária Tropical, v.32, n.1, p.21-28, 2002. Disponível em: <http://www.revistas.ufg.br/index.php/pat/article/view/2436>

CARDOSO, E.D.; SÁ, M.E.; HAGA, K.I.; BINOTTI, F.F.S.; COSTA, E. Qualidade fisiológica e composição química de sementes de Brachiaria brizantha em função do condicionamento osmótico. Revista de Agricultura Neotropical, Cassilândia-MS, v.2, n.2, p.42-48, 2015. Disponível em: <http://periodicos.uems.br/novo/index.php/ agrineo/article/view/4963/2902>

CARDOSO, E.D.; SÁ, M.E.; HAGA, K.I.; BINOTTI, F.F.S.; NOGUEIRA, D.C.; FILHO, W.V.V. Desempenho fisiológico e superação de dormência em sementes de Brachiaria brizantha submetidas a tratamento químico e envelhecimento artificial. Semina: Ciências Agrárias, Londrina, v.35, n.1, p.21-38, 2014. Disponível em: < http://dx.doi.org/10.5433/1679-0359.2014v35n1p21> doi: 10.5433/16790359.2014v35n1p21

COSTA, C.J., ARAÚJO, R.B.; BÔAS, H.D.C.V. Tratamentos para a superação de dormência em sementes de Brachiaria humidicola (Rendle) Schweick. Pesquisa Agropecuária Tropical, 41:519-524, 2011. Disponível em: <http://dx.doi.org/10.5216/pat.v41i4.15100> doi: 10.5216/pat.v41i4.15100

FERREIRA, D.F. SISVAR: a computer statistical analysis system. Ciência Agrotecnologia, Lavras, v.35, n.6, p.1039-1042, 2011. 
LABOURIAU, L.G. A germinação das sementes. Organização dos Estados Americanos. Programa Regional de Desenvolvimento Científico e Tecnológico. Série de Biologia: Monografia 24, 1983.

LABOURIAU, L.G.; VALADARES, M.E.B. On the germination of seeds of Calotropis procera (Ait.) Ait. F. Anais da Academia Brasileira de Ciências, v.48, p.263-284, 1976.

LACERDA, M.J.L.; CABRAL, J.S.R.; SALES, J.F.; Freitas, K.R.; Fontes, A.J. Superação da dormência de sementes de Brachiaria brizantha cv. "Marandu". Semina: Ciências Agrárias, Londrina, v. 31, n. 4, p. 823-828, 2010. Disponível em: <http://dx.doi.org/10.5433/1679-0359.2010v31n4p823> doi: 10.5433/1679$0359.2010 v 31 \mathrm{n} 4 \mathrm{p} 823$

LAGO, A.A.; MARTINS, L. Qualidade fisiológica de sementes de Brachiaria brizantha. Revista Agropecuária Brasileira, Brasília, v. 33, n. 2, p. 199-204, 1998.

MACEDO, E. C.; GROTH, D.; LAGO, A. A. Efeito de escarificação com ácido sulfúrico na germinação de sementes de Brachiaria humidicola (Rendle) Schweick. Pesquisa Agropecuária Brasileira, Brasília, v. 29, n. 3, p. 455-460, 1994.

MAGUIRE, J.D. Speed of germination-aid in selection and evaluation for seedliNg emergence and vigor. Crop Science, Madison, v.2, n.1, p.176-177,1962.

PARREIRA, M.C.; CARDOZO, N.P; GIANCOTTI, P.R.F.; ALVES, P.L.C.A. Superação de dormência e influência dos fatores ambientais na germinação de sementes de Spermacoce latifolia. Revista Brasileira de Ciências Agrárias, v.6, n.3, p.427-431, 2011. Disponível em: <http://dx.doi.org/ 10.5039/agraria.v6i3a1031> doi: 10.5039/agraria.v6i3a1031

RANAL, M.A.; SANTANA, D.G. How and why to measure the germination process? Revista Brasileira de Botânica, v.29, p.1-11, 2006.

SILVA, A.L.M.S.; TORRES, F.E.; GARCIA, L.L.P.; MATTOS, E.M.; TEODORO, P.E. Tratamentos para quebra de dormência em Brachiaria brizantha. Revista de Ciências Agrárias, v.37, n.1, p.37-41, 2014.

TOMAZ, C.A.; MARTINS, C.C.; SANCHES, F.G.; VIEIRA, R.D. Time reduction for surinam grass seed germination test. Ciência e agrotecnologia, Lavras, v.39, n.5, p.488-497, 2015. Disponível em: <http://dx.doi.org/10.1590/S141370542015000500007> doi: 10.1590/S1413-70542015000500007

USDA (2014) Relatórios da Agência. Disponível em: <http://www.usda.gov>. Acesso em: 5 de Outubro de 2015.

ZUFFO, A.L.; ANDRADE, F.R.; SILVA, L.M.A., MENEZES, K.O.; SILVA, R.L; PIAUILINO, A.C. Profundidade de semeadura e superação de dormência no crescimento inicial de sementes de Brachiaria dictyoneura (Fig. \& De Not.) Stapf 
(1919) cv. Llanero. Ceres, Viçosa, v. 61, n.6, p.948-955, 2014. Disponível em: <http://dx.doi.org/10.1590/0034-737X20146106009> doi: 10.1590/0034737X20146106009 